\title{
PENGUJIAN USABILITY USER INTERFACE DAN USER EXPERIENCE APLIKASI E-READER SKRIPSI BERBASIS HYPERTEXT
}

\author{
Ardiansyah, Muhammad Imam Ghazali \\ Program Studi Teknik Informatika \\ Fakultas Teknologi Industri - Universitas Ahmad Dahlan \\ Jl. Prof. Dr. Soepomo, Janturan, Yogyakarta \\ ardiansyah@tif.uad.ac.id,imamghazhali07@gmail.com
}

\begin{abstract}
Abstrak
Membaca dokumen hypertext yang berbentuk web lebih menyulitkan jika dibandingkan dengan dokumen teks linier seperti $P D F$. Selain itu, membaca dokumen hypertext sebagai representasi sebuah buku atau skripsi elektronik memiliki kelemahan dari sisi user interface dan user experience. Padahal website telah menjadi media elektronik yang jamak digunakan para pembaca untuk mengakses dan membaca berbagai macam informasi. Penelitian ini bertujuan untuk mengukur tingkat usability desain aplikasi eReader skripsi berbasis hypertext. Penelitian ini menggunakan paket pengujian SUS (System Usability Scale) untuk mengukur usability desain aplikasi dan SEQ (Single Ease Question) untuk mengukur tingkat kemudahan setiap fungsi desain aplikasi yang dikembangkan. Komparasi dilakukan antara sistem eReader yang saat ini digunakan yaitu Digilib UAD dengan desain aplikasi eReader skripsi hypertext. Hasil komparasi ini untuk mengetahui tingkat perbedaan usability antara keduanya. Penelitian ini melibatkan sebanyak tiga puluh responden yang dipilih secara acak yang dikelompokkan ke dalam dua kondisi. Sebanyak lima belas responden yang menggunakan eReader skripsi Digilib UAD dan lima belas responden yang menggunakan desain aplikasi eReader berbasis hypertext. Hasil pengujian menunjukkan bahwa skor SUS desain aplikasi eReader skripsi hypertext adalah sebesar 82.2 yang berarti bahwa desain aplikasi eReader skripsi yang dikembangkan memiliki usability yang excellent menurut para responden, sehingga bisa diterima dengan baik nantinya oleh para pengguna. Hasil komparasi menunjukkan bahwa tingkat usability desain aplikasi yang dikembangkan lebih tinggi dan berbeda secara signifikan
\end{abstract}

dibandingkan dengan usability aplikasi Digilib UAD yang sebesar 63.8. Hasil komparasi menunjukkan bahwa para pengguna lebih menerima dan puas dengan desain aplikasi eReader skripsi hypertext dibanding dengan eReader skripsi Digilib UAD.

Kata kunci :

Usability, eReader skripsi, SUS, hypertext

\begin{abstract}
Reading hypertext documents is more difficult than reading traditional linear text. Reading hypertext document as a representation of electronic book or thesis has lack the user interface and user experience. Website is widely used by readers as an electronic media to access and read the various information. This study aims to measure usability level of eReader thesis based hypertext. This study uses a SUS (System Usability Scale) questionnaire package to measure the usability of the application design and SEQ (Single Ease Question) to determine the level of convenience of each function of the applications proposed. Comparison is conducted between eReader system that is currently used in Digilib UAD and hypertext based eReader system to determine which one is more usable. The study involved thirty participants were selected randomly into two conditions. Fifteen participants use Digilib $U A D$ eReader and another fifteen participants use hypertext-based eReader system. The results showed SUS score for hypertext based eReader system 82.2, which means that the proposed eReader application has excellent usability according to the participants, so it will be well received by the users. Furthermore, the comparison showed that the usability level of proposed system is higher and significantly different compared with the usability of Digilib UAD by 63.8.
\end{abstract}


Thus, it means the user is received and satisfied with the proposed eReader system compared with the Digilib UAD eReader system.

Keywords :

Usability, eReader skripsi, SUS, hypertext

\section{Pendahuluan}

Laporan hasil penelitian atau skripsi mahasiswa biasanya dikemas dalam sebuah skripsi yang tercetak. Laporan skripsi dikelola oleh lembaga yaitu perpustakaan. Seiring dengan semakin meluasnya dokumen elektronik yang berwujud paperless, maka skripsi juga mulai disediakan dalam bentuk elektronik. Format yang paling banyak digunakan adalah PDF (portable document format).

Perpustakaan kampus menyediakan akses skripsi secara daring melalui peramban dan PDF reader. Beberapa kakas yang populer untuk keperluan ini bisa dilihat melalui ePrints, Digital Library ITB dan Digilib UAD serta sebagian besar kampus-kampus di Indonesia.

Sebagai media informasi, web sudah kerap digunakan sebagai buku elektronik/digital $(\mathrm{Gu}, \mathrm{Wu}$, $\& \mathrm{Xu}, 2015)$. Akan tetapi, sampai saat ini masih jarang ditemukan skripsi yang tersedia dalam format web/hypertext yang langsung bisa dibaca di peramban. Padahal, banyak penelitian yang membuktikan bahwa membaca dokumen menggunakan web/hypertext terbukti membantu meningkatkan pemahaman konten di dalamnya (Erhan, 2014). Hal ini menunjukkan bahwa web sudah bisa menjadi alternatif format laporan skripsi yang digunakan selain yang sudah ada saat ini yaitu bentuk tercetak dan PDF.

Menyajikan skripsi dalam bentuk hypertext ternyata juga memiliki kelemahan yaitu di sisi desain user interface dan user experience pengguna. Hal ini terlihat dari penelitian yang dilakukan $\mathrm{Li}$, Tseng, \& Chen (2016) dikarenakan tidak menerapkan desain yang baik, sehingga mengakibatkan pembaca membutuhkan waktu yang lama untuk menyelesaikan bacaannya. Selain itu, desain yang buruk juga bisa menyebabkan pembaca mengalami disorientasi (lost in hyperspace) ketika membaca dokumen hypertext (Theng et al, 1996).
Untuk itu penelitian ini akan mengembangkan dan menguji user interface dan user experience untuk aplikasi eReader skripsi berbasis web.

\section{Penelitian Terkait}

Hypertextbook adalah sumber bahan ajar di perguruan tinggi yang dirancang serta dibuat untuk bisa dibaca melalui peramban web standar seperti Firefox, Internet Explorer, Netscape, Mozilla, Chrome, Opera dan lain sebagainya (Cunningham, AB., Lennox, JE., Ross, 2008). Beberapa penelitian telah dilakukan terkait pengembangan buku berbasis web, seperti yang dilakukan oleh Card \& Robertson (1996) tentang WebBook dan Web Forager.

Rizkiana (2015) telah memulai penelitian tentang dokumen buku digital berbasis HTML (hypertextbook) khusus membuat sampul bukunya. Penelitian ini telah menghasilkan desain sampul hypertextbook yang usable dan bisa diterima (acceptable) oleh pembaca. Selain sampul buku juga memiliki struktur dan tata letak antara lain daftar isi, nomor halaman, bab, sub-bab, gambar, tabel, grafik hingga daftar isi. Untuk membantu pembaca dalam menavigasi dokumen buku elektronik maka selalu disediakan fitur navigasi dokumen misalnya page turning yang dikembangkan oleh Liesaputra \& Witten (2009), Marshall \& Bly (2005) dan Tajika, Yonezawa, \& Mitsunaga (2008).

Sebagian besar eBook Reader telah mendukung fungsi-fungsi anotasi seperti highlight, membuat catatan (note) dan menambah bookmark. Anotasi adalah pemberian tanda pada sebuah dokumen di halaman tertentu. Setiap anotasi secara digital biasanya tersusun atas dua hal yaitu pertama content berupa catatan/komentar atau mengarsir (highlight) teks dan kedua adalah anchor yang biasanya merupakan informasi yang digunakan untuk memposisikan suatu penjelasan dalam dokumen (Brush, Bargeron, Gupta, \& Cadiz, 2001).

Aktivitas yang biasanya dilakukan pada saat membaca buku adalah melihat daftar isi, glosari, daftar pustaka, melihat nomor halaman, formula/rumus, gambar, dan tabel. Pada buku cetak, pembaca dapat melihat setiap halaman dengan menggunakan indera penglihatan dan sentuhan. Mencari bab tertentu, pembatas buku dengan cara dilipat, tulisan-tulisan yang dicoret, dilingkari, bahkan diarsir akan sangat mudah dilakukan dan ditemukan kembali pada buku cetak. Semua tanda 
tersebut menunjukkan adanya isyarat/tanda kontekstual (contextual cue).

Anotasi yang dilakukan baik di buku cetak maupun eBook ditujukan untuk memudahkan pembaca dalam meningkatkan pemahaman pada bagian-bagian yang sudah dianotasi. Hal ini sangat penting diperlukan agar dengan adanya anotasi tersebut pembaca bisa dengan mudah dan cepat untuk menemukan kembali bagian yang sudah diberi anotasi tersebut. Akan tetapi, untuk melakukan hal tersebut pembaca harus sering melakukan scrollbar dragging agar bisa menemukan kembali bagian dari eBook yang sudah ditandai. Padahal dengan melakukan scrollbar dragging, maka pembaca akan selalu melewati bagian/bab lembaran buku yang tidak relevan dan tidak jarang pembaca terlanjur membaca bagian yang tidak berkaitan dengan informasi yang dicari. Hal ini dikarenakan tanda/isyarat spasial pada eBook tidak seperti pada buku cetak. Artinya dengan kondisi seperti ini, banyak waktu yang terbuang karena pembaca harus melalui bagian-bagian yang tidak relevan/penting sebelum sampai pada bagian yang dimaksud.

Hypertextbook memiliki navigasi standar sebuah web, yaitu bersifat statis dengan terdiri dari node, link, contextual link dan non-contextual link. Adapun untuk struktur bukunya sendiri tetap menampilkan daftar isi lengkap yang terdiri dari bab dan sub-bab. Riset terkait revisitation dan navigasi pada hypertext sudah banyak dikembangkan serta diterapkan seperti berikut:

1. Tool grafik pada peramban seperti tombol History, Back, Forward, Bookmarks (Shen \& Prior, 2011), Peta Situs (Cockburn \& Greenberg, 1999) dan hyperlink (Weinreich, Obendorf, Herder, \& Mayer, 2006) (Aggarwal, Oostendorp, \& Indurkhya, 2014)

2. Tinjauan secara grafis dan spasial (Conklin \& Begeman, 1988), (Nielsen, 1990), (Marshall, Shipman III, \& Coombs, 1994), (Cockburn \& Jones, 2000), dan WebView (Cockburn, Greenberg, Mckenzie, Jasonsmith, \& Kaasten, 1999).

3. Peta dan isyarat visual (Brusilovsky \& Rizzo, 2003), (Li, Chen, \& Yang, 2013) dan (Song, Chen, \& Li, 2013).

4. Adaptive navigation (Brusilovsky, Chavan, \& Farzan, 2004).

\section{III.METODE}

\section{III.1 Alat dan Bahan}

Desain yang diuji pada penelitian ini adalah aplikasi eReader skripsi $P D F$ milik Digilib UAD (desain A) seperti yang ditunjukkan gambar 2 dan desain aplikasi eReader skripsi yang dikembangkan yang berjalan pada peramban (desain B) yang ditunjukkan pada gambar 1. Desain B dibangun berbasis HTML5. Desain eReader ini memiliki tujuh fungsi yaitu F01 (Login), F02 (Baca skripsi dari halaman Home), F03 (Baca skripsi berdasarkan Prodi), F04 (Baca skripsi berdasarkan pencarian), F05 (Komentar), F06 (Like) dan F07 (Logout). Dokumen skripsi yang digunakan untuk pengujian adalah dalam bahasa Indonesia. Perangkat keras yang digunakan adalah satu unit $P C$ dengan sistem operasi Windows 7, aplikasi peramban Mozilla Firefox. Alat ukur (instrumen) yang digunakan yaitu skenario, lembar observasi dan angket (kuisioner).

Kinerja task diukur menggunakan pengujian Post-Task Study dengan metode Single Ease Question (SEQ). Pengujian ini digunakan untuk mengukur kemudahan yang dirasakan pengguna setelah menyelesaikan semua skenario/task yang diberikan (Sauro \& Lewis, 2012). Kinerja usability diukur menggunakan pengujian post study dengan metode System Usability Scale (SUS) (Brooke, 1996) (Brooke, 2013). SUS merupakan paket pengujian usability yang efektif dan handal untuk digunakan pada berbagai produk dan aplikasi (Bangor, Kortum, \& Miller, 2009). SEQ terdiri dari satu pertanyaan dengan skala likert 1 sampai 7 dari pilihan sangat sulit, sulit, tidak mudah, cukup, tidak sulit, mudah, dan sangat mudah. SUS terdiri dari 10 pertanyaan dengan menggunakan skala likert 1 sampai 5 . Pertanyaan nomor ganjil $(1,3,5,7,9)$ merupakan pertanyaan yang bernada positif. Sedangkan pertanyaan nomor genap $(2,4,6,8,10)$ merupakan pertanyaan yang bernada negative seperti yang ditunjukkan pada tabel 1. Setiap pertanyaan diberi bobot antara 0-4. Pada pertanyaan ganjil (bernada positif), skor tiap pertanyaan dihitung dengan cara bobot tiap pertanyaan (xi) dikurangi 1, sehingga ditulis $x i-1$. Begitu pula pertanyaan genap (bernada negatif), skor dihitung dengan cara 5 dikurangi bobot tiap pertanyaan (xi) sehingga ditulis menjadi 5-xi. Total skor didapatkan dengan menjumlahkan seluruh skor tiap pertanyaan (genap maupun ganjil). Sedangkan skor SUS didapat dengan cara mengkalikan total skor dengan 2.5. Skor akhir SUS 
akan berada pada kisaran 0-100. Berdasarkan skor akhir SUS tersebut akan bisa diketahui seberapa tinggi tingkat usability dan akseptabilitas (acceptable) desain sistem aplikasi yang dikembangkan. Penilaiannya berdasarkan tiga kategori yaitu Not Acceptable dengan rentang skor SUS 0-50.9, Marginal 51-70.9, dan Acceptable 71100. Responden diminta menjawab semua butir pertanyaan yang diisi setelah pengguna selesai menggunakan sistem secara keseluruhan.
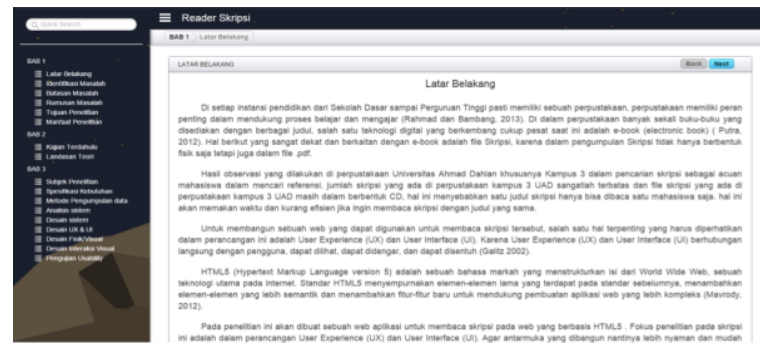

Gambar 1. Desain aplikasi eReader skripsi hypertext
Tabel 1. Daftar pertanyaan SUS

\begin{tabular}{ll}
\hline \hline No & \multicolumn{1}{c}{ Pertanyaan } \\
\hline \hline 1 & $\begin{array}{l}\text { Saya sepertinya akan sering menggunakan aplikasi ini. } \\
\text { Saya melihat ada bagian fitur aplikasi ini yang cukup } \\
\text { merepotkan, yang mestinya hal itu tidak perlu terjadi }\end{array}$ \\
3 & $\begin{array}{l}\text { Saya rasa aplikasi ini mudah digunakan } \\
\text { Saya sepertinya akan membutuhkan bantuan seorang } \\
\text { teknisi agar bisa lancar menggunakan aplikasi ini. }\end{array}$ \\
5 & $\begin{array}{l}\text { Saya rasa fitur-fitur aplikasi ini sudah terintegrasi dengan } \\
\text { baik satu sama lain }\end{array}$ \\
6 & $\begin{array}{l}\text { Saya menemukan terlalu banyak ketidak konsistenan } \\
\text { dalam aplikasi ini }\end{array}$ \\
7 & $\begin{array}{l}\text { Saya pikir orang-orang akan sangat cepat bisa } \\
\text { menggunakan aplikasi ini }\end{array}$ \\
8 & $\begin{array}{l}\text { Saya rasa aplikasi ini sangat sulit untuk digunakan } \\
\text { Saya merasa mantap menggunakan aplikasi ini }\end{array}$ \\
10 & $\begin{array}{l}\text { Saya mesti belajar banyak hal terlebih dahulu sebelum } \\
\text { mulai menggunakan aplikasi ini }\end{array}$ \\
\hline \hline
\end{tabular}

Tabel 2. Hasil tabulasi skor tiap pertanyaan $S U S$

\begin{tabular}{ccccccccccc}
\hline \hline Responden & $\mathbf{q 1}$ & $\mathbf{q} 2$ & $\mathbf{q 3}$ & $\mathbf{q 4}$ & $\mathbf{q 5}$ & $\mathbf{q 6}$ & $\mathbf{q} \mathbf{4}$ & $\mathbf{q 8}$ & $\mathbf{q 9}$ & $\mathbf{q 1 0}$ \\
\hline \hline 1 & 4 & 1 & 5 & 3 & 5 & 2 & 5 & 1 & 5 & 3 \\
2 & 5 & 2 & 5 & 3 & 5 & 2 & 5 & 1 & 4 & 3 \\
3 & 5 & 1 & 5 & 1 & 5 & 2 & 5 & 1 & 4 & 1 \\
4 & 5 & 2 & 5 & 3 & 5 & 2 & 5 & 1 & 4 & 2 \\
5 & 5 & 2 & 4 & 2 & 4 & 2 & 5 & 1 & 4 & 2 \\
6 & 4 & 2 & 4 & 2 & 4 & 1 & 5 & 1 & 4 & 2 \\
7 & 3 & 2 & 4 & 3 & 4 & 1 & 5 & 1 & 4 & 2 \\
8 & 5 & 2 & 4 & 3 & 4 & 2 & 4 & 1 & 5 & 2 \\
9 & 5 & 3 & 4 & 2 & 5 & 1 & 4 & 2 & 5 & 3 \\
10 & 5 & 1 & 5 & 1 & 5 & 1 & 5 & 1 & 5 & 1 \\
11 & 2 & 1 & 5 & 3 & 4 & 3 & 5 & 2 & 4 & 3 \\
12 & 4 & 2 & 5 & 2 & 3 & 2 & 4 & 2 & 4 & 5 \\
13 & 4 & 2 & 5 & 2 & 3 & 2 & 5 & 2 & 4 & 3 \\
14 & 3 & 2 & 4 & 1 & 4 & 2 & 5 & 1 & 5 & 1 \\
15 & 4 & 1 & 5 & 3 & 5 & 1 & 5 & 1 & 5 \\
\hline \hline
\end{tabular}

\section{III.2 Prosedur}

Pelaksanaan pengujian usability dilakukan dengan mendatangi satu per satu responden untuk dimintai kesediaan menggunakan sistem eReader skripsi Digilib UAD dan desain eReader skripsi hypertext yang diusulkan. Responden dibagi menjadi dua grup yaitu $\mathrm{S} 1(N=15)$ dan $\mathrm{S} 2(N=15)$. Responden diberikan laptop, lembar skenario, lembar angket $S E Q$ dan SUS. Pertama-tama responden diberikan penjelasan tentang desain aplikasi eReader skripsi ini beserta fungsionalitasnya. Selanjutnya responden diberikan lembar skenario untuk mencoba ketujuh fungsi yang tersedia di lembar tersebut. Responden harus mengikuti setiap langkah yang sudah dituliskan dalam lembar skenario. Responden tidak diperkenankan melakukan task di luar skenario. Setiap selesai mengerjakan satu task, responden diminta untuk memilih pilihan pada angket yang tersedia sebagai bagian dari pengujian SEQ. Tabel 3 merupakan daftar fungsi desain aplikasi eReader beserta task yang dilakukan oleh responden. 
Sedangkan tabel 4 adalah salah satu contoh lembar skenario beserta angket yang mesti diisi responden setelah melakukan skenario yang diberikan. Setelah menyelesaikan seluruh fungsi maka selanjutnya responden diminta untuk mengisi lembar angket $S U S$.

Responden pengujian ini terdiri dari 30 mahasiswa Universitas Ahmad Dahlan yang sedang berkunjung ke perpustakaan kampus 3. Responden berasal dari berbagai fakultas dan program studi.

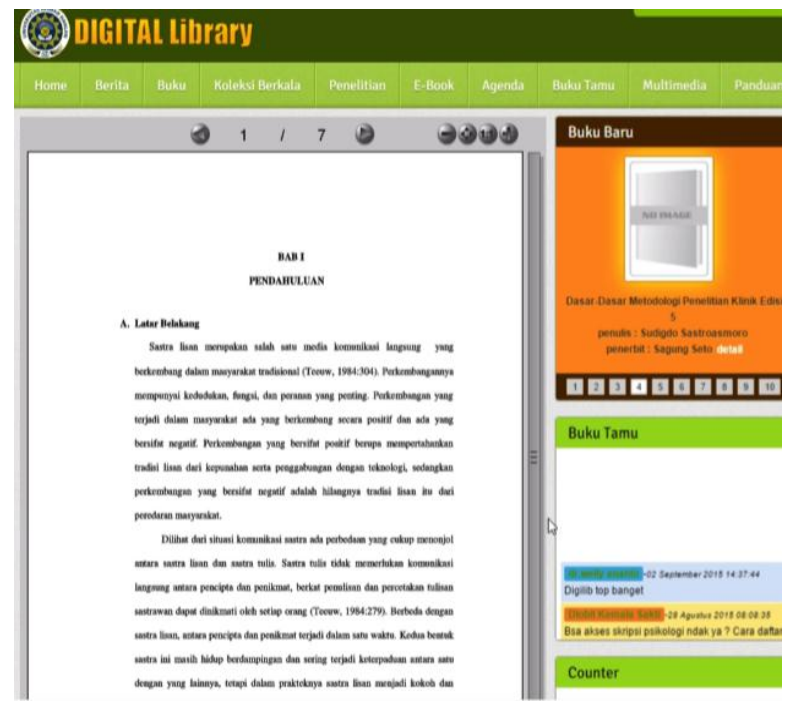

Gambar 2 Aplikasi eReader Digilib UAD (Desain A)

\section{III.2 Analisis Data dan Hasil}

Data dianalisis menggunakan aplikasi Microsoft Excel. Tendensi sentral median digunakan untuk mengetahui nilai pengujian post-task. Median digunakan untuk mengetahui tendensi sentral pada variabel pengujian yang bertipe categorical (Tarquinio, 2015). Sedangkan skor SUS S2 dianalis dan diinterpretasikan menggunakan kisaran rating penerimaan (acceptability), skala nilai (grade) dan adjective rating seperti yang ditunjukkan pada gambar 3. Selanjutnya dilakukan komparasi antara skor SUS S1 dan S2. Sampel yang digunakan adalah sampel bebas karena terdapat dua kelompok responden yang berbeda. Pengujian t-test digunakan untuk mengetahui signifikansi perbedaan skor SUS antara S1 dan S2 apabila selang kepercayaan (confidence interval) saling tumpang tindih atau bersinggungan.

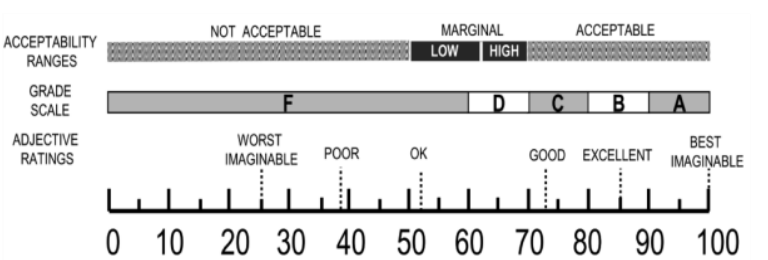

Gambar 3. Rating dan skala konversi skor rerata $S U S$

Tabel 3. Daftar Fungsi dan Task eReader skripsi Hypertext

\begin{tabular}{|c|c|c|}
\hline No & "Nama Fungsi & "Task/ Tugas \\
\hline$\overline{\mathrm{F}} \mathrm{F01}$ & "Login & $\begin{array}{l}\text { Memasukkan username dan } \\
\text { password untuk login kedalam } \\
\text { aplikasi. }\end{array}$ \\
\hline F02 & $\begin{array}{l}\text { Baca Skripsi dari } \\
\text { halaman Home }\end{array}$ & $\begin{array}{l}\text { Membaca skripsi dari halaman } \\
\text { Home, pilih salah satu skripsi } \\
\text { yang di tampilkan. }\end{array}$ \\
\hline F03 & $\begin{array}{l}\text { Baca Skripsi } \\
\text { berdasarkan } \\
\text { program studi }\end{array}$ & $\begin{array}{l}\text { Mencari menu fakultas, pilih } \\
\text { salah satu fakultas/prodi untuk } \\
\text { membaca skripsi berdasarkan } \\
\text { fakultas/prodi. }\end{array}$ \\
\hline F04 & $\begin{array}{l}\text { Baca Skripsi } \\
\text { berdasarkan } \\
\text { pencarian }\end{array}$ & $\begin{array}{l}\text { Mencari menu "Search" untuk } \\
\text { mencari skripsi yang diinginkan. }\end{array}$ \\
\hline F05 & Komentar & $\begin{array}{l}\text { Memilih salah satu skripsi } \\
\text { kemudian temukan icon komentar } \\
\text { untuk mengomentari skripsi. }\end{array}$ \\
\hline F06 & Like & $\begin{array}{l}\text { Memilih salah satu skripsi dan } \\
\text { temukan icon like pada skripsi } \\
\text { yang di pilih kemudia klik icon } \\
\text { like. }\end{array}$ \\
\hline F07 & Logout & $\begin{array}{l}\text { Mencari tombol logout kemudian } \\
\text { klik tombol logout untuk keluar } \\
\text { dari sistem. }\end{array}$ \\
\hline
\end{tabular}

Tabel 4. Contoh skenario untuk fungsi F02

\begin{tabular}{llr}
\hline \hline No & Tugas yang dikerjakan & Ya/Tidak \\
\hline \hline 1 & Berada di Halaman Home & \\
2 & Scroll kebawah sampai menemukan daftar \\
& skripsi \\
3 & Pilih salah satu skripsi yang akan dibaca \\
4 & Tampil Pop-up berisi deskripsi skripsi \\
5 & Baca Deskripsi Skripsi \\
6 & $\begin{array}{l}\text { Klik tombol Read More untuk membaca } \\
\text { skripsi }\end{array}$ & \\
7 & Tampil Reader untuk membaca skripisi
\end{tabular}

Dari hasil analisis data pengujian post-task didapatkan bahwa median untuk semua fungsi F01 sampai F07 bernilai "sangat mudah", yang berarti semua fungsi sangat mudah untuk digunakan oleh 
pengguna. Gambar 4 menunjukkan grafik hasil pengujian post-task yang menggunakan metode $S E Q$.

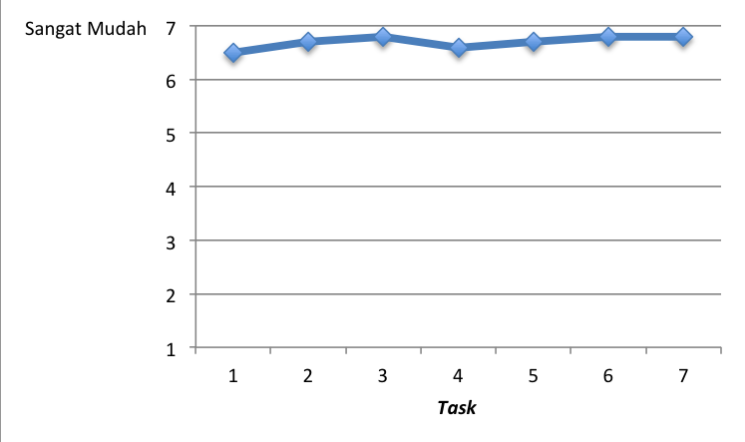

Gambar 4. Grafik hasil pengujian SEQ

Berdasarkan pengolahan data seperti yang ditabulasikan pada tabel 2 diperoleh skor SUS sebesar 82.2, yang berarti bernilai $B$ - jika dikonversikan menurut standar Bangor, Kortum, \& Miller (2008), bernilai $A$ kalau menurut standar Sauro (2011) dan masuk dalam kategori Acceptable jika dikonversikan menurut kisaran rating penerimaan. Dengan demikian, maka desain aplikasi eReader hypertext (S2) memiliki usability yang excellent menurut para responden.

Selanjutnya hasil komparasi antara skor SUS S1 dan S2 didapatkan bahwa S2 berbeda signifikan dibanding S1. Skor S1 diperoleh yaitu sebesar 63.8 dan S2 82.2. Kedua skor ini menunjukkan bahwa usability desain aplikasi eReader skripsi hypertext memiliki tingkat Acceptable yang lebih tinggi dibanding usability aplikasi Digilib UAD. Jika diinterpretasikan berdasarkan grafik pada gambar 5, maka terlihat perbedaan keduanya adalah signifikan. Hal ini terlihat pada error bar selang kepercayaan yang tidak saling tumpang tindih. Sehingga dengan kondisi demikian tidak perlu dilakukan pengujian lanjutan yaitu uji $t$-test. Perbedaan yang signifikan ini menunjukkan bahwa para pengguna lebih menerima dan puas dengan usability desain aplikasi eReader skripsi hypertext dibanding dengan eReader skripsi Digilib UAD saat ini.

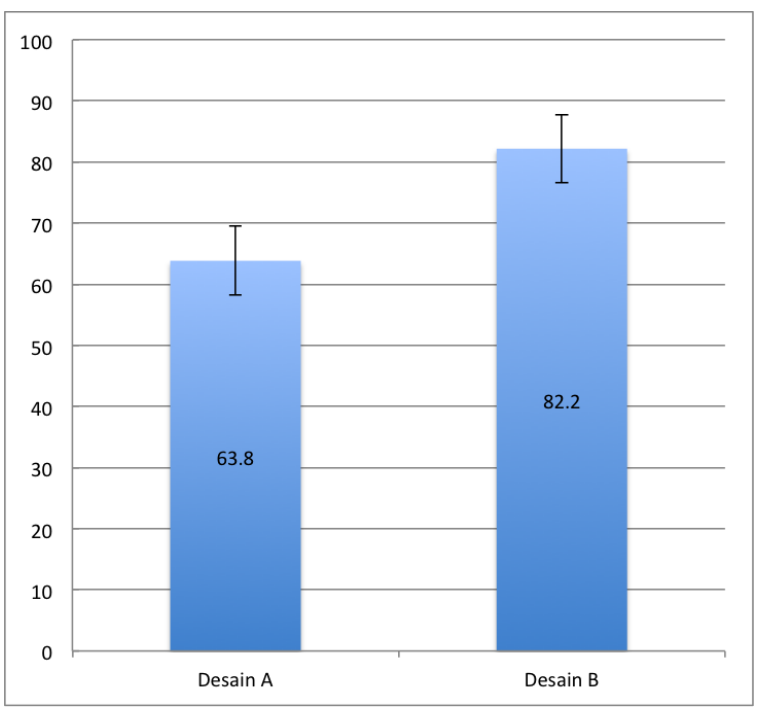

Gambar 5. Grafik perbandingan skor $S U S \mathrm{~S} 1$ dan $\mathrm{S} 2$

\section{KESIMPULAN DAN SARAN}

Penelitian ini berhasil menghasilkan desain user interface dan user experience aplikasi eReader skripsi berbasis hypertext. Hasil pengujian menunjukkan bahwa desain yang dibuat memiliki tingkat akseptabilitas yang tinggi sehingga bisa diterima dan siap digunakan oleh pengguna. Begitu pula hasil komparasi dengan Digilib UAD menunjukkan bahwa pengukuran usability desain eReader yang dikembangkan memiliki tingkat usability yang lebih tinggi dan signifikan.

Akan tetapi, pengujian yang dilakukan belum memasukkan aspek task completion rate dan task time. Sehingga di pengujian berikutnya perlu dimasukkan kedua unsur tersebut. Selanjutnya perlu ditinjau kembali penggunaan paket angket SUS sebagai instrument pengujian aplikasi berbasis web atau hypertext. Hal ini dikarenakan selama ini SUS sebenarnya lebih sering digunakan untuk mengukur usability dan learnability berbagai jenis sistem perangkat keras maupun perangkat lunak, sehingga tidak selalu cocok untuk mendiagnosa usability sistem berbasis web. Sauro (2013) lebih menyarankan agar menggunakan SUPRQ (Standardized Universal Percentile Rank-Questionnaire) atau WAMMI (Website Analysis and MeasureMent Inventory) sebagai alat pengujian sistem berbasis web. 


\section{REFERENSI}

Aggarwal, S., Oostendorp, H. Van, \& Indurkhya, B. (2014). Automating Web-Navigation Support Using a Cognitive Model. In 4th International Conference on Web Intelligence, Mining and Semantics. Hyderabad, India. Retrieved from http://dl.acm.org/citation.cfm?id=2611077

Bangor, A., Kortum, P., \& Miller, J. (2009). Determining What Individual SUS Scores Mean: Adding an Adjective Rating Scale. Journal of Usability Studies, 4(3), 114-123.

Bangor, A., Kortum, P. T., \& Miller, J. T. (2008). An Empirical Evaluation of the System Usability Scale. International Journal of HumanComputer Interaction, 24(June 2015), 574-594. http://doi.org/10.1080/10447310802205776

Brooke, J. (1996). SUS - A quick and dirty usability scale. In P. Jordan, B. Thomas, \& B. Weerdmeester (Eds.), Usability Evaluation in Industry (pp. 189-194). London: Taylor \& Francis. Retrieved from http://cui.unige.ch/isi/iclewiki/_media/ipm:test-suschapt.pdf

Brooke, J. (2013). SUS : A Retrospective. Journal of Usability Studies, 8(2), 29-40. Retrieved from http://www.usabilityprofessionals.org/upa_publ ications/jus/2013february/brooke1.html/nhttp:// www.usability.gov/how-to-andtools/methods/system-usability-scale.html

Brush, a. J. B., Bargeron, D., Gupta, A., \& Cadiz, J. J. (2001). Robust annotation positioning in digital documents. Proceedings of the SIGCHI Conference on Human Factors in Computing Systems - CHI '01, 285-292. http://doi.org/10.1145/365024.365117

Brusilovsky, P., Chavan, G., \& Farzan, R. (2004). Social Adaptive Navigation Support for Open Corpus Electronic Textbooks. In Adaptive Hypermedia and Adaptive Web-Based Systems (pp. 24-33). Springer Berlin Heidelberg.

Brusilovsky, P., \& Rizzo, R. (2003). Using Maps and Landmarks for Navigation between Closed and Open Corpus Hyperspace in Web-based Education, 1-15.

Card, S. K., \& Robertson, G. G. (1996). The WebBook and the Web Forager: An Information Workspace for the World-Wide
Web. In CHI '96 (pp. 111-117). Vancouver, BC, Canada.

Cockburn, A., \& Greenberg, S. (1999). Issues of Page Representation and Organisation in Web Browser's Revisitation Tools. Australian Journal of Information Systems, 7, 120-127.

Cockburn, A., Greenberg, S., Mckenzie, B., Jasonsmith, M., \& Kaasten, S. (1999). WebView: A Graphical Aid for Revisiting Web Pages. In OzCHI'99: Australian Conference on Computer-Human Interaction (pp. 15-22). Wagga, Wagga. Retrieved from http://www.cosc.canterbury.ac.nz/\%7Eandy/pa pers/webViewOzCHI.pdf

Cockburn, A., \& Jones, S. (2000). Which Way Now? Analysing and Easing Inadequacies in WWW Navigation. International Journal of HumanComputer Studies, 45(1), 105-129.

Conklin, J., \& Begeman, M. L. (1988). glBIS : A Hypertext Tool for Exploratory Policy Discussion. ACM Transactions on Information Systems (TOIS), 6(4), 303-331.

Cunningham, AB., Lennox, JE., Ross, R. (2008). What is a hypertextbook? Retrieved from http://www.coe.montana.edu/biofilmbook/PRE FACE_MATL/Overview.htm

Erhan, D. (2014). Effect of hypertextual reading on academic success and comprehension skills. Educational Research and Reviews, 9(14), 447-455. http://doi.org/10.5897/ERR2013.1405

Gu, X., Wu, B., \& Xu, X. (2015). Design, development, and learning in e-Textbooks: what we learned and where we are going. Journal of Computers in Education, 2(1), 2541. http://doi.org/10.1007/s40692-014-0023-9

Li, L.-Y., Chen, G.-D., \& Yang, S.-J. (2013). Construction of cognitive maps to improve ebook reading and navigation. Computers \& Education, $\quad 60(1), \quad 32-39$. http://doi.org/10.1016/j.compedu.2012.07.010

Li, L.-Y., Tseng, S.-T., \& Chen, G.-D. (2016). Effect of hypertext highlighting on browsing, reading, and navigational performance. Computers in Human Behavior, 54, 318-325. http://doi.org/10.1016/j.chb.2015.08.012

Liesaputra, V., \& Witten, I. H. (2009). Computer 
graphics techniques for modeling page turning. International Journal on Digital Libraries, 10(2-3), 93-121. http://doi.org/10.1007/s00799-009-0055-3

Marshall, C. C., \& Bly, S. (2005). Turning the page on navigation. In Proceedings of the 5th ACM/IEEE-CS joint conference on Digital libraries - JCDL '05 (pp. 225-234). New York, New York, USA: ACM Press. http://doi.org/10.1145/1065385.1065438

Marshall, C. C., Shipman III, F. M., \& Coombs, J. H. (1994). VIKI: Spatial Hypertext Supporting Emergent Structure. In Proceedings of the 1994 ACM European conference on Hypermedia technology (pp. 13-23).

Nielsen, J. (1990). The art of navigating through hypertext: Lost in hyperspace. Communications of the ACM, 33(3), 296-310.

Rizkiana, F. (2015). Look and Feel Sampul dan Daftar Isi Hypertextbook berdasarkan aspek User Experience dan User Interface. Universitas Ahmad Dahlan.

Sauro, J. (2011). Measuring Usability with the System Usability Scale (SUS). Retrieved January $\quad 1, \quad 2015, \quad$ from http://www.measuringu.com/sus.php

Sauro, J. (2013). 10 Things to Know About the System Usability Scale (SUS): MeasuringU. Retrieved January 12, 2015, from http://www.measuringu.com/blog/10-thingsSUS.php

Sauro, J., \& Lewis, J. R. (2012). Quantifying the User Experience: Practical Statistics for User Research. (S. Elliot, Ed.) (I). USA: Elsevier.

Shen, S., \& Prior, S. D. (2011). Revisiting Revisitation in Computer Interaction: Organic. Design Principle and Practice, 5.

Song, Y.-C., Chen, G.-D., \& Li, L.-Y. (2013). Improving E-Book Reading with Information Cues: An User Investigation and Suggestion. In 2013 IEEE 13th International Conference on Advanced Learning Technologies (pp. 261263). http://doi.org/10.1109/ICALT.2013.81

Tajika, T., Yonezawa, T., \& Mitsunaga, N. (2008). Intuitive page-turning interface of e-books on flexible e-paper based on user studies.
Proceeding of the 16th ACM International Conference on Multimedia - MM '08, 793. http://doi.org/10.1145/1459359.1459489

Tarquinio, A. (2015). SmartHeart CABG Edu: First Prototype and Preliminary Evaluation. Advances in Distributed Computing and Artificial Intelligence Journal, 4(1), 22-33.

Theng, Y. L., Jones, M., \& Thimbleby, H. (1996). Lost in hyperspace: Psychological problem or bad design? In APCHI'96 (pp. 387-396).

Weinreich, H., Obendorf, H., Herder, E., \& Mayer, M. (2006). Off the Beaten Tracks: Exploring Three Aspects of Web Navigation. In $W W W$ '06 Proceedings of the 15th international conference on World Wide Web (pp. 133-142). New York, NY, USA.

Ardiansyah, Muhammad Imam Ghazali 